\title{
Vincent van Gogh's illness: acute intermittent porphyria?
}

\author{
Loretta S Loftus, Wilfred Niels Arnold
}

Vincent van Gogh died 101 years ago, at the peak of his artistic power, of complications from a self inflicted gunshot wound. His hectic life culminated with four extremely productive years but was prefaced by all manner of personal doubts and professional frustrations. There were several well documented episodes of serious illness, some requiring hospitalisation, over the span of his 37 years. The widespread popularity of van Gogh's paintings and the place he occupies in any analysis of creativity have aroused interest in his medical problems and conjecture about their influence on his work as well as his life.

In contrast to the terse and limited antemortem diagnoses by attending physicians,' posthumous speculations have been profuse, and yet a consensus on precise diagnosis has not been reached. ${ }^{2}$ The collected letters ${ }^{3}$ written by Vincent, his brother Theo and, to a lesser extent, his other family and friends, remain the best source of unembellished descriptors of his medical problems, albeit in lay terms. It is clear that Vincent suffered from some type of psychosis with exacerbation factors; Hemphill, for example, concluded that van Gogh was a manic depressive who developed confusional episodes and fits due to his addiction to the liqueur called absinthe. ${ }^{4}$

Vincent's ailment was characterised by episodes of acute mental derangement and disability, which were separated by intervals of lucidity and creativity. ${ }^{1}$ Moreover, attending physicians - and the artist himself -were surprised and encouraged by the rapidity of the recoveries after each crisis. ${ }^{12}$ His serious illness developed late in the third decade and played into the fourth $^{3}$; elicited frequent gastrointestinal complaints and at least one bout of constipation requiring medical intervention, ${ }^{13}$; caused fits with hallucinations, both auditory and visual ${ }^{3}$; and evoked seizures. ${ }^{1}$ The periods of incapacitating depression and physical discomfort were severe and grave enough to provoke self mutilation $^{3}$ and eventual suicide. Some of his bouts of sickness may have been associated with fever and sexual impotence. ${ }^{3}$ His ailment was exacerbated by overwork; malnutrition and fasting; environmental exposure; excessive ingestion of alcohol, especially the liqueur called absinthe; and a proclivity for camphor and other terpenes. ${ }^{35}$ The symptoms were palliated during institutionalisation with better diet and abstinence from alcohol and treatment with bromide. ${ }^{3}$ In spite of the severity of the attacks he did not experience any permanent, functional disability after any attack. ${ }^{12}$ There was a family history of mental illness. ${ }^{12}$ Notwithstanding the restraints of retrospective analysis on a definitive diagnosis, the gamut of symptoms and responses is consistent with acute intermittent porphyria, a hereditary metabolic disease that provides a unifying hypothesis.

The first case of acute intermittent porphyria was reported by Stokvis ${ }^{6}$ just one year before van Gogh's death, but the disease did not enter the practising diagnostician's armamentarium until decades later. ${ }^{7}$ The disease arises from the partial deficiency of a liver

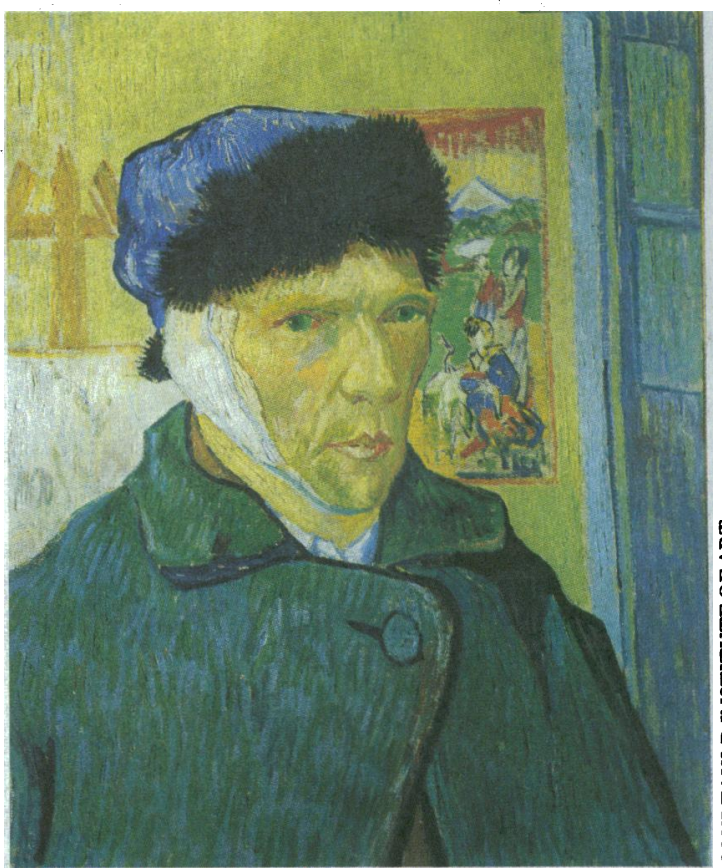

“Self portrait with severed ear," Arles, fanuary 1889

enzyme, porphobilinogen deaminase, which results in improper orchestration of haem biosynthesis. The physiological consequences are correlated with the increased activity of $\delta$-aminolevulinate synthase and raised concentrations of $\delta$-aminolevulinic acid and porphobilinogen. Those metabolites are also excreted in the urine. Freshly voided urine is colourless, but on exposure to air and light it becomes dark or a wine red colour after several hours. A definitive diagnosis can be made on the basis of chemical tests for the specific metabolites and enzymic analyses. ${ }^{8}$ The disease follows autosomal dominant inheritance: if one parent is a carrier then, on average, half the children will bear the defective gene. ${ }^{9}$ Most importantly, the expression of neurological and other symptoms depends on lifestyle and exposure to precipitating factors. Early examples of acute intermittent porphyria were revealed as a response to new drugs -initially to sulphonal, later to barbiturates, and subsequently to other drugs, some steroid hormones, alcohol, and sundry organic compounds. ${ }^{10}$ Offending compounds are recognised by their induction of $\delta$-aminolevulinate synthase in an avian cell culture system. ${ }^{11}$ Other exacerbation factors are infections and malnutrition. Low carbohydrate and low protein diets are especially detrimental, ${ }^{12}$ and fasting can precipitate an attack of porphyria. ${ }^{13}$

The clinical manifestations of acute intermittent porphyria have been recorded more often in females than males, but in both sexes the symptoms rarely occur before puberty. The peak decade for onset is from age 20 to 29 (onset is usually earlier in women than in men), but the disease sometimes remains latent 


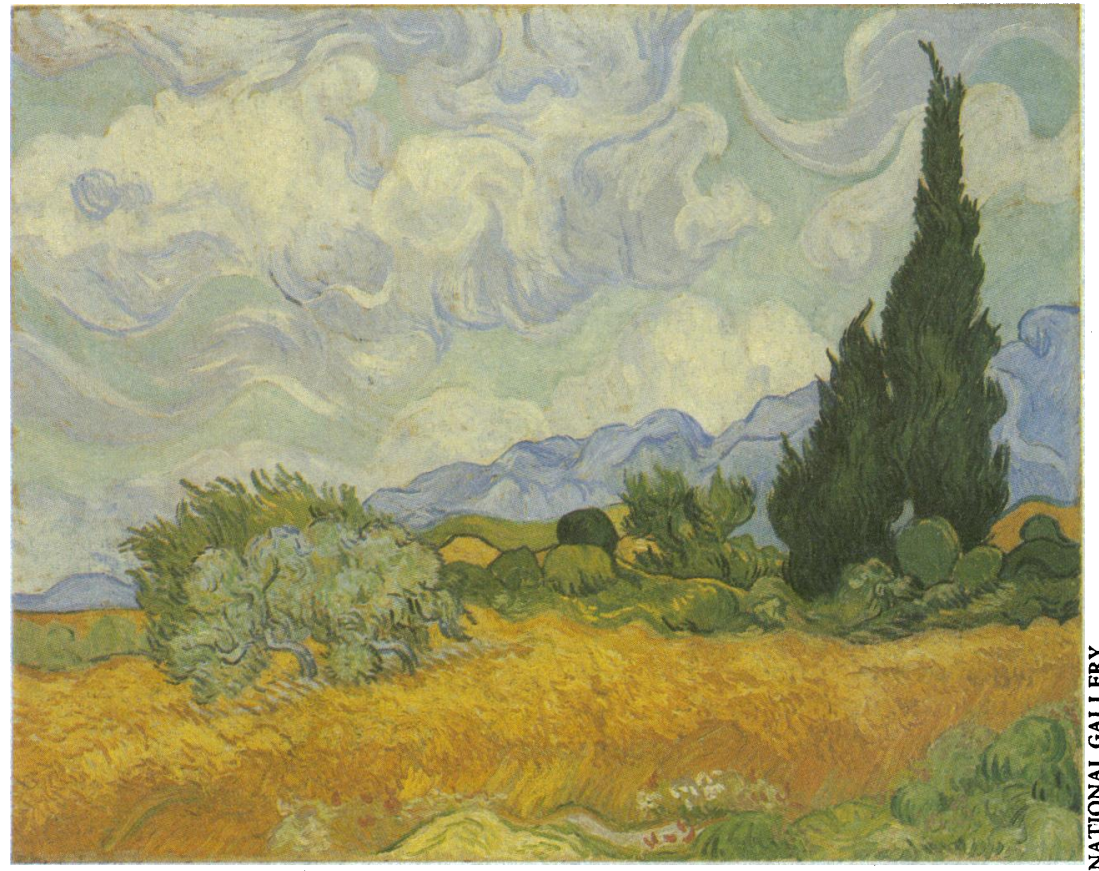

“Yellow wheat," Saint-Remy, Fuly 1889

throughout a lifetime. Because precipitant factors are so important for clinical expression, the observed degree of penetrance in a family can be quite low. ${ }^{89}$ Tabulations of the most common hallmarks emphasise abdominal pain and other gastrointestinal complaints, symptoms referrable to the peripheral and central nervous systems, and signs of autonomic neuropathy including tachycardia and hypertension. ${ }^{8}$ Hypertension induced by porphyria can cause early onset renal failure. ${ }^{14}$ Bladder dysfunction may result in urinary retention. The optic nerves, occipital lobes, and sexual function have occasionally been affected. Premonitory symptoms include restlessness and irritability; attacks develop rapidly; resolution is unpredictable and may occur in days or sometimes weeks. Seizures sometimes occur during severe crises but antiseizure drugs, with the notable exception of bromides, may adversely affect this disease. ${ }^{8}$

\section{A unifying hypothesis}

All of the hallmarks of Vincent's illness can be accommodated by this overview of acute intermittent porphyria. The most important and well documented are the gastrointestinal complaints, neurological disturbances, age of onset, jagged time course, and the exacerbation factors of inadequate nutrition and absinthe abuse. These aspects are well documented, but dark or reddish urine is not mentioned in the correspondence. It may, however, have escaped observation. Vincent's living quarters were often primitive; for example, the "Yellow House" in Arles had no toilet and he was forced to use the facilities at the hotel next door. ${ }^{3}$ We assume he relieved himself in the field while painting. Furthermore, even freshly voided urine during crises of acute intermittent porphyria is often normal colour - the pigmentation comes with retention in the bladder or on aging. ${ }^{8}$

Arnold suggested that van Gogh's fondness for absinthe developed into a pica for terpenes, the documented examples being thujone, camphor, and pinene. ${ }^{5}$ It is worth noting that eucalyptol ( 1,8 cineole), a constituent of camphor and wormwood oils, can be a precipitating agent for acute intermittent porphyria. ${ }^{15}$ Van Gogh used reckless doses of camphor oil against insomnia ${ }^{3}$ and absinthe contained a variety of essential oils including wormwood..$^{16}$ Other evidence, which is less definitive but supplemental, includes a bout of unexplained eye problems and possible aphasia in the Arles Hospital. ${ }^{3}$ The case for acute intermittent porphyria is strengthened by the family history.

Both Tralbaut and Hulsker remarked on the similarity of the illnesses of Vincent and Theodorus. ${ }^{17}$ There were numerous exchanges between the brothers along those lines, including Vincent's reference to "our $\mathrm{W}$ neurosis [as] a fatal inheritance." " At 19, Theo suffered a life threatening illness which included fevers; he was incapacitated for seven weeks. ${ }^{17}$ Ten years later he had $\stackrel{\text { S? }}{7}$ "serious nervous afflictions, so bad that he couldo not move," according to his future brother in law. ${ }^{17}$ 듬 Three months later Theo admitted that his own mental $\frac{\bar{\rho}}{\bar{D}}$. illness contributed to current stressful interactions $\stackrel{\otimes}{\otimes}$ with Vincent. ${ }^{17}$ Leg pain recurred. ${ }^{3}$ According to Emile Bernard, within two months of Vincent's suicide Theo "lost his reason and collapsed; he was para-. lyzed." "Theo suffered further leg pains and hallucina- $\vec{\overrightarrow{ }}$ tions, became very irritable and occasionally violent, $\stackrel{\circ}{\circ}$ experienced urine retention, and died just six months윽 after his brother. ${ }^{17}$ Although others have suggested kidney stones and uraemia (and even a broken heart) as the cause of Theo's illness, ${ }^{17}$ we believe that the leg pains, mental illness, paralysis, and $\infty$ renal failure support a diagnosis of acute intermittent. porphyria.

Vincent's youngest sister, Willemina, spent the latter half of her 79 years in a psychiatric asylum. 은 She may also have suffered from acute intermittent $N$ porphyria, although the lack of further documentation $\vec{\square}$ makes her case much more speculative. The youngest ${ }^{\mathbb{D}}$ brother, Cornelis, committed suicide at 23; again the $\mathbb{D}$ medical history is scant. The other sisters, Elisabeth믐 and Anna, lived 77 and 75 years, respectively, without $\stackrel{\mathbb{Q}}{-}$ any indication of crises and supposedly did not inherit $\overrightarrow{0}$ the defective gene. Vincent's mother led a seemingly healthy life and died at 88, although her family is reputed to have had some incidence of "epilepsy." Vincent's father, the Reverend Theodorus van Gogh, died from a stroke at 63 ; his studies for the church had been interrupted by serious illness; he was judged by at $\frac{0}{\circ}$ least one commentator not to have been in very good $\varrho$ health most of his life.' One of the father's brothers, $\overline{\overrightarrow{0}}$ Vincent (Uncle Cent), retired early, was "reduced to 3 suspicious helplessness and continual suffering,"3 and died at 68 ; another brother, Hendrik (Uncle Hein), retired at age 58 for undocumented health reasons and died five years later. ${ }^{17}$ Of Vincent's parents the father may be the more likely (obligate) carrier of acute 0 intermittent porphyria. He led a careful and balanced life in his "post in the wilderness" and may have avoided the precipitating factors that affected three of his six children.

Chronic heavy metal poisoning, particularly with lead, will cause peripheral neuropathy, but seizures and confusional states are uncommon in affectedo adults. ${ }^{8}$ Although poisoning from pigments has been suggested in connection with Vincent ${ }^{2}$ it seems much ${ }^{N}$ less likely with Theo or Wil, who were not exposed tow any degree. We favour a diagnosis of acute intermittent porphyria over bipolar affective disorder ${ }^{18}$ because ofo the facile reversibility and relatively short duration of Vincent's crises. The gastrointestinal complaints and? the convulsions that mimic epilepsy are not indicative 0 of manic depressive psychosis, but the differential diagnosis is complicated by absinthe abuse, which was known to evoke these symptoms. ${ }^{516}$

We suggest that Vincent van Gogh suffered from acute intermittent porphyria, exacerbated by mal- $\Omega$ nutrition and absinthe abuse. This provides a reason-0 able working hypothesis for the nature of his illness. All of the documented symptoms can be accommo-? dated, and the family history provides additional support. To have three of the six children show signs of acute intermittent porphyria would agree with the 
statistical expectation for autosomal dominant inheritance, although this high degree of penetrance is rare. $^{89}$

Peters and others emphasised good nutritional habits and complete avoidance of precipitant causes as the greatest priority in treating acute intermittent porphyria. ${ }^{19}$ In that context it is unsettling to read in van Gogh's letters the recurring theme that sickness, or something less than full health, is compatible with or even encourages creative work. While contemplating leaving the asylum at St Remy and returning to the north Vincent wrote, "As for eating a lot, I dobut if I were my doctor, I'd forbid it. I don't see any advantage for myself." 3 If he suffered from acute intermittent porphyria his own advice was the worst possible.

Details of the references to van Gogh's letters may be obtained from the authors.

1 Tralbaut ME. Vincent van Gogh. New York: Alpine Fine Arts, 1981. 2 Lubin AJ. Stranger on the earth: a psychological biography of Vincent van Gogh. New York: Henry Holt, 1987

3 The complete letters of Vincent van Gogh. 3 vols. 2nd ed. Boston: New York Graphics Society, 1978.

4 Hemphill RE. The illness of Vincent van Gogh. Proc R Soc Med 1961;54: 1083-8.
Arnold WN Vincent van Gogh and the thujone connection. JAMA 1988.260; 3042-4.

6 Stokvis BJ. Over twee zeldzame kleurstoffen in urine van zieken. Weekbla Nederlandsch Tijdschrift Geneeskunde 1889;2:409-17.

7 With TK. A short history of porphyrins and the porphyrias. In $f$ Biochem 1980;11:189-200.

8 Kappas A, Sassa S, Galbraith RA, Nordmann Y. The porphyrias. In: Scrive CR, Beaudet AL, Sly WS, Valle D, eds. The metabolic basis of inherited disease. 6th ed. New York: McGraw-Hill, 1989:1305-65.

9 Waldenstrom J. The porphyrias as inborn errors of metabolism. $A m \mathcal{f} \mathrm{Med}$ 1957;22:758-73.

10 Moore MR. International review of drugs in acute porphyria. Int $\mathcal{f}$ Biochem 1980;12:1089-97.

11 Granick S. The induction in vitro of the synthesis of $\partial$-aminolevulinic acid synthetase in chemical porphyria: a response to certain drugs, sex hormones, and foreign chemicals. I Biol Chem 1966;241:1359-75.

12 Welland FH, Hellman ES Gaddis EM, Collins A, Hunter GW, Tschudy DP. Factors affecting the excretion of porphyrin precursors by patients with acute intermittent porphyria. I: The effect of diet. Metabolism 1964;13: $232-50$

13 Knudsen KB, Sparberg M, Lecocq F. Porphyria precipitated by fasting N Engl f Med 1967;277:350-1.

14 Laiwah AACY, Mactier R, McColl KEL, Moore MR, Goldberg A. Earlyonset chronic renal failure as a complication of acute intermittent porphyria. Qf Med 1983;52:92-8.

15 Bickers DR, Miller L, Kappas A. Exacerbation of hereditary hepatic porphyria by surreptitious ingestion of an unusual provocative agentmouthwash preparation. N Engl f Med 1975;292:1115-6.

16 Arnold WN. Absinthe. Sci Am 1989;260(June):112-7.

17 Hulsker J. Vincent and Theo van Gogh: a dual biography. Ann Arbor: Fulle Technical Publications, 1990.

18 Kolb LC, Brodie HKH. Modern clinical psychiatry. Philadelphia: Saunders, 1982

19 Peters HA. Acute hepatic porphyria. In: Johnson RT, ed. Current therapy in neurologic disease 1985-1986. Philadelphia: B C Decker, 1986:317-21.

\title{
Médecins Sans Frontières: 20 years old
}

\author{
Alexander Dorozynski
}

They are known as "the French doctors." They treat the wounded in Lebanon and Angola, set up refugee camps in Thailand and Kurdistan, denounce violations of human rights in Iraq and Cambodia, care for street children in Antananarivo (Madagascar) and orphans in Romania. They are for the most part young, and they are seen as daredevils with panache. They are, in fact, working under a highly structured organisation, Médecins Sans Frontières, now collaborating with the World Health Organisation, the United Nation's High Commission for Refugees, the International Red Cross, and other government or non-governmental humanitarian and aid organisations. MSF, "doctors without frontiers," was founded almost exactly 20 years ago, on 21 December 1971, and is now the world's largest and probably best known private humanitarian organisation.

Every year about a thousand MSF doctors, nurses, and logistics experts travel to "hot spots" worldwide, sometimes illegally and often at the risk of their lives, to carry out the mission defined in the charter written in 1971: "Médecins Sans Frontières bring their help to all victims of natural catastrophe, collective accidents, and belligerent situations, without discrimination of race, politics, religion, or philosophy." MSF has provided emergency medical care and relief in more than 80 countries; it has established refugee camps and organised epidemiological training, all the while affirming its independence from any government or pressure group. "We have been close to misery, death, disease, violence, and we have been strengthened, better armed," says Dr Xavier Emmanuelli, one of the founders and a very active honorary president. "We have forged a tool, solid, pragmatic, of a dimension never achieved before... yet we have remained free, rebellious, independent."

MSF was founded by physicians who had cared for the wounded and the sick during the Biafra war, and others who had responded to an appeal by the French medical newspaper Tonus to fly to eastern Pakistan (soon to become Bangladesh) to provide emergency relief during floods that devastated the region. As a fledgling organisation it served as a source of volunteer physicians, who joined missions run by organisations such as the International Red Cross, Save the Children or the Order of Malta.

MSF established a small office in Paris in 1972, run by a few voluntary physicians and Tonus journalists with funds provided chiefly by donations from French physicians, and started organising its own missions relief to victims of an earthquake in Nicaragua medical assistance in Honduras, and treatment of the wounded in the Lebanon war-where MSF teams worked on all sides, in cities bombed by Syrians or Israelis, in Christian and Moslem zones, in Palestinian camps.

An important step was taken in 1976 when an advertising agency, Eleuthera, organised-free of charge - a nationwide campaign that brought MSF to the attention of the French people and triggered increased donations. In the same year MSF opened its first refugee camp, in Thailand.

In the years that followed MSF kept growing and set up its central structure, with permanent staff, a logistic cell, and streamlined fundraising activities. While growing in size, MSF organised medical teams adapted to specific situations and opened up sections in Belgium, Switzerland, and Holland and later in Luxembourg and Spain. In 1980 MSF medical teams went to war torn Afghanistan. Increasing international recognition led MSF to emphasise its role not only as a humanitarian organisation but as "a sentry of human rights." The very presence of an MSF team, it is felt, could deter human rights violations. The "right to initiative" was reaffirmed: interventions are determined by medical needs, and if a government refuses entry the teams enter the country clandestinely since "assistance to individuals in danger is above the rules of non-interference into the affairs of a country."

By 1984 there were "French doctors" teams in 20 